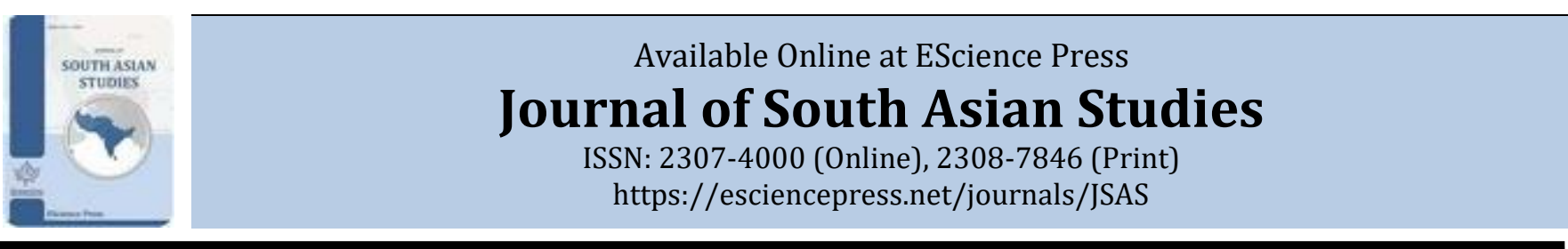

\title{
Employee Job Satisfaction in Higher Educational Institutes: A Review of Theories
}

\author{
aAli Junaid Khan*, bMuhammad Azhar Bhatti, 'Altaf Hussain, dRashid Ahmad, aJawad Iqbal \\ a Institute of Business, Management \& Administrative Sciences, The Islamia University of Bahawalpur, Bahawalpur, \\ Pakistan. \\ bc Department of Economics, Islamia University of Bahawalpur, Bahawalpur, Pakistan. \\ d School of Economics, Bahauddin Zakariya University, Multan, Pakistan. \\ *Corresponding Author Email ID: junaaidkhan@yahoo.com
}

\section{A B S T R A C T}

Employee Job satisfaction is an indication of how happy you are with your job. A person will feel confident and enthused about their work if they adhere to this value of job satisfaction. As a result, it is no surprise that the topic of their job satisfaction comes up frequently in conversation. Job-satisfaction theories from Maslow to Lock have all been proposed to try to explain or understand the phenomenon of job satisfaction and motivation. Analyzing these theories, Factors that contribute to employee job satisfaction change over time and cultural aspects are very important. In this study, a descriptive research design was used, and conclusions were drawn using a theory-based approach. According to the findings, job satisfaction of academic staff can be improved by implementing theories of satisfaction and motivation in higher educational institutes. Job satisfaction of academic staff leads towards the delivery of quality education resulting in student satisfaction and better university performance. This study has several implications for researchers and Policymaker. It shows that it makes no difference whether theories are correct or incorrect; rather, it is determined by the environment in which they are used. Theories must be redesigned to incorporate the most recent results in human psychology.

Keywords: Job satisfaction, Motivation, Higher Education, Theories of Satisfaction.

\section{INTRODUCTION}

Any country's education system plays a critical role in society, particularly in the generation of new information. Higher educational institutions (HEIs) are the most common places where knowledge is transferred. The success, vision, and mission of a higher education institution are largely determined by the work of the academic staff. A great education system is built on a solid foundation of highly qualified academic professionals. Staff in academic institutions reflect the country's values and the nation's builders (Stanovskaet al., 2017). Academics are a valuable resource in the higher education sector, and they play an important role in helping institutions of higher learning achieve their goals. Teaching and administrative staff make up a large part of the quality of higher education, as do processes and functions. Teaching staff must now, more than ever, be able to perceive and apply the demands that need to be altered and applied in their job in order to keep up with changing educational trends (Wisniewska, Grodowski, 2016). The quality of education provided, and the achievement of corporate goals rely heavily on the happiness of employees in their jobs. Employee performance and organizational commitment are closely linked, making job satisfaction an important research topic (Junaid et al., 2021). This depends on how "engaged" and "committed" educators are in their work, which in turn determines the competitiveness of the education sector. Strategic human resource management's most important goal is to figure out how to attract and keep top academic talent while also monitoring their performance (Van den Brink et al., 2013; Khan et al., 2021).

According to O'Leary et al. (2009), job satisfaction is the joy or fulfillment people get from their jobs. Job satisfaction is an attitude that manifests itself at work as 
individual employee behavior and can have an influence on an organization's success. Employees who are pleased with their job employees are more likely to enhance their performance, commit to the company, minimize absenteeism, and be more enthusiastic about their jobs. It is important in both emerging and established countries, as well as for both public and private institutions. Studies on work happiness in profitmaking industrial and service organizations predominate, and little study has been conducted to uncover the characteristics that contribute to employee job satisfaction (Toker, 2011).

Academics, scholars, policymakers, and university management are always increasingly interested in the job satisfaction of university staff. According to Toker (2011), this increased interest stems from the fact that HEIs are labor-intensive, with the bulk of their expenditures going to staff, and their efficiency strongly relies on the work of their administrative and academic employees (Mohammad et al., 2011). As a result, this study is an attempt to focus on motivation and work satisfaction theories that might be extremely useful in increasing the job happiness of academic personnel in Pakistani HEIs.

Several theories have been presented to describe and examine the phenomena of job satisfaction (Maslow, Vroom, Adams, Herzberg, McGregor, and others), and this attempt is ongoing since changes occur, and the prior theory must be altered or replaced with a new model. Theories regarding how employment influences job satisfaction evolve throughout time and across regions. As a result, it is critical that practitioners keep current with the latest research on these concerns. Authors such as Kebede and Demeke (2017) and Okoli (2018) have undertaken studies on motivation and job satisfaction in HEIs in Kenya, Nigeria, and Ethiopia. In Pakistan's higher education institutes, these theories are not widely known. Several theories, such as Maslow's and Herzberg's, can be utilized to discover the best elements for academic staff job satisfaction.

\section{LITERATURE REVIEW Job Satisfication}

Job satisfaction is usually viewed as a sense of fulfillment or enjoyment that individuals gain from their jobs (O'Leary et al., 2009) and it is positively connected with employee development and wellbeing (Junaid, Bashir, Nasim, \& Ahmad, 2021). Good working relationships with colleagues and coworkers, self-control over vacation, and appropriate resources are all signs of job satisfaction. The success of any organization largely depends on employees' level of satisfaction with their job. This is also true in HEIs because teaching staff is a central point for measuring performance (Khan \& Iqbal, 2020a, 2020b). It has been shown that employees who are happy in their jobs are more productive, which increases the productivity of the organization. According to Lockwood (2007), heads of departments in HEIs are at the center of service production and therefore have a significant impact on their employees' morale. Managing higher education institutes effectively is in doubt if teaching staff is dissatisfied and uncommitted (Clark et al., 1996).

Job satisfaction has three facets: intrinsic, extrinsic, and general reinforcement elements (Gunluet al., 2009). If intrinsic job satisfaction is to be assessed, it must take into account such elements as success in the job and the ability to use one's abilities as well as self-defectiveness, authority, and activity (Gunlu et al., 2009). Advancement, business policy, supervisor-human, and supervisor-technical relations, salary, and recognition are all important in determining extrinsic satisfaction. Job satisfaction is produced by adding together intrinsic and extrinsic variables (Gunluet al., 2009). Many studies show that there is a relationship between job satisfaction and employee performance.

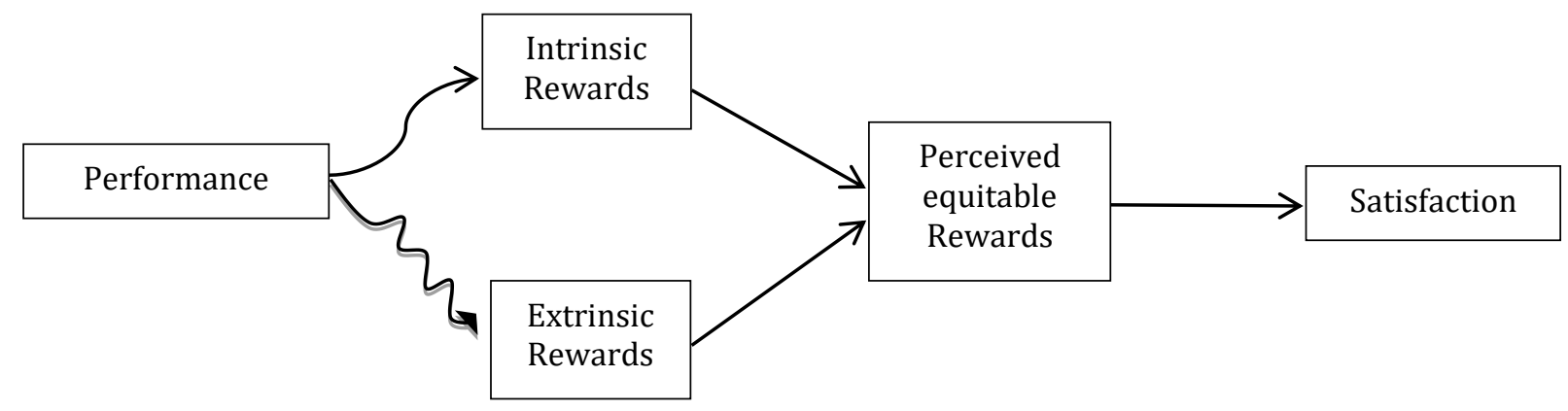

Figure 1. Relationship between job satisfaction and employee performance.

Source: Figure is drawn by the authors based on literature of job satisfaction. 
In the work and organizational literature, job satisfaction has received a lot of attention. This is since many experts feel that job satisfaction patterns do affect labor market behavior such as productivity, effort, employee absenteeism, and staff turnover. Work satisfaction is also viewed as a critical indicator of overall personal wellbeing as well as a good predictor of employees' intents or decisions to leave a job.

Job satisfaction and motivation among academic staff have a significant influence on the quality of educational institutions and the growth of students' learning (Stanovskaet al., 2017), who represent the future workforce in many industries. In the education industry, competitiveness is measured by how happy and satisfied people are with their professions, or how "engaged" and committed they are to them. The major purpose of strategic human resource management is to recruit and retain academic personnel, particularly talented individuals, as well as track their performance. Van den
Brink and colleagues (Van den Brink \&colleagues, 2013). Employee motivation and happiness have become pillars of modern human resource management, as only a strong incentive system can help businesses improve their competitiveness and value (Javeria et al., 2013).

Academic staff satisfaction and motivation are critical for their performance and the success of a higher education institution (de Louders Machado et al., 2011). Teaching, research, environmental contribution, participation in events, instructional work, and a sense of belonging to the academic staff are all examples of academic staff motivation. The HEIs environment, capacity to practice teaching, chances to practice teaching as academic staff, prestige linked with the instructor's employment, and possibility for research work are all examples of satisfaction. Consequently, we picked five theories to analyze how these concepts work in Pakistani higher education institutions.

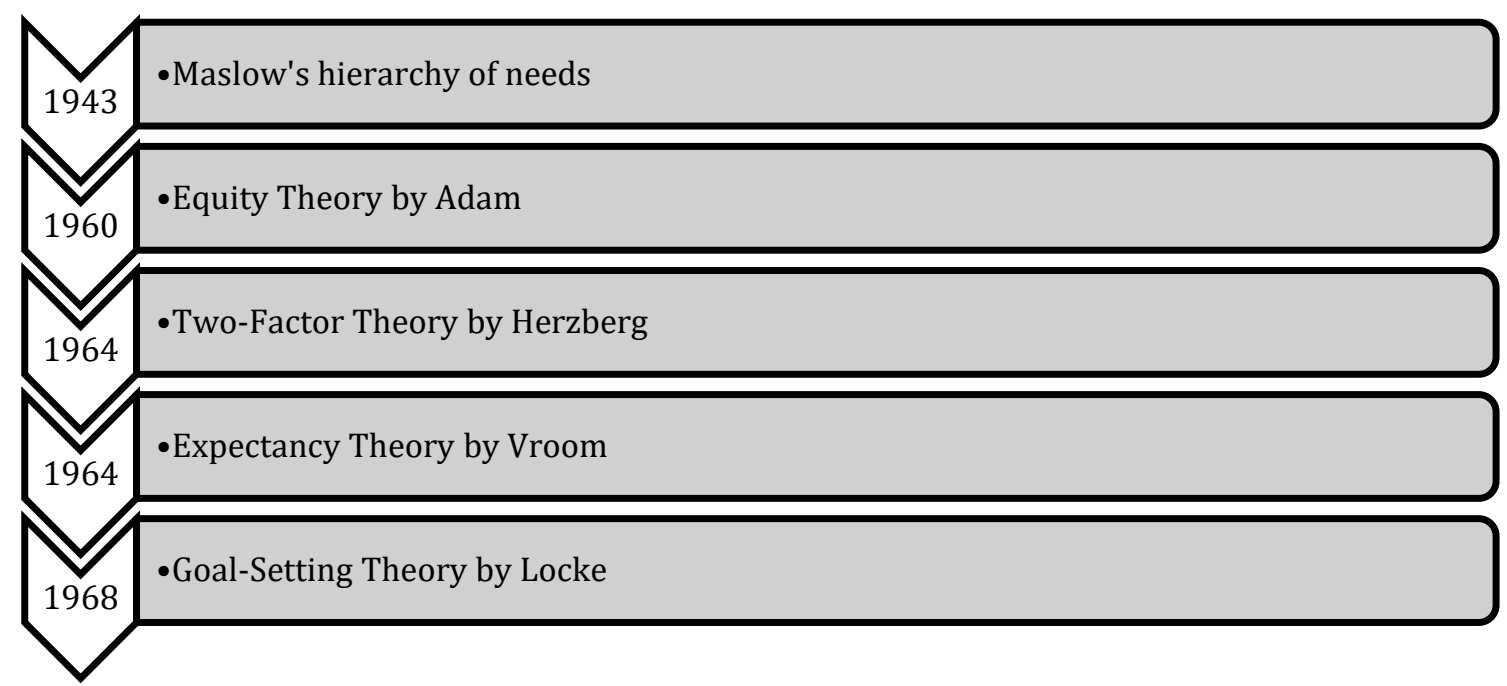

Figure 2. Theories of Satisfaction \& Motivation.

Source: This figure is made by authors as recommended by reviewer to show the overall summary of theories discussed in this article.

\section{HIERARCHY OF NEED THEORY BY MASLOW}

As far as motivation and contentment theories go, Maslow's hierarchy of needs may be the most wellknown (Kaur, 2013). Maslow suggested that individual motivational demands may be arranged into a hierarchy based on human psychology and professional experiences. Some requirements are more important than others. Having met a need removes the motivation for the individual (Luthan, 2005). According to Firkhanet al., (2021), failing to address fundamental human needs disrupts the human spirit, and as a result, people fail to attain self-satisfaction in terms of their growth, profession, or occupation. To mention a few, basic needs include physiological requirements, security requirements, affection requirements, self-esteem, and the degree of one's own perfection (Maslow, 1954).

When these levels of need are met, teacher job satisfaction will increase, according to Rosneeet al. Teachers' physiological needs include things like paying salaries or compensation, as well as providing lounges, 
facilities, and other places where they can work. Once the physiological level's requirements have been completed, the safety level's standards must be met as well. According to Zaid et al. (2020), the degree of safety includes the right to a sense of security as well as a sense of well-being for the individual, their family, their property, and even their place of employment. A person's need to be liked and accepted must be addressed once the first two stages of security have been achieved. This stage necessitates the flawless fulfillment of both spiritual and social requirements.

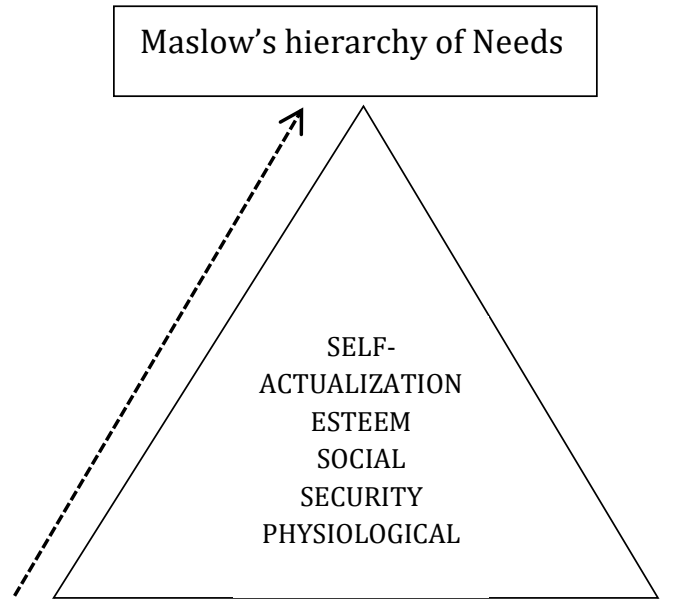

Figure 3. Maslow's Hierarchy of Need.

Source: (Maslow, 1943).

To be accepted at HEIs, one must first meet their level of self-esteem before they can be satisfied with the work they have done. According to Fauziyana et al. (2020), human beings require respect and recognition from those around them at this stage. One way to address teachers' needs, according to Norazmiet al. (2020), is to give them praise or appreciation in some form. Zaid et al. (2021) assert that job satisfaction can be achieved when all of these conditions are met. In agreement with this assertion, a teacher's job satisfaction will be high if they are able to meet all the above requirements, including a sufficient salary, the feeling of belonging, and being treated equitably by the management of HEIs.

Education and human development have benefited greatly from Maslow's theory (Eenet al., 2021). Teachers' subjective job satisfaction can be gauged using the criteria outlined in this theory. For example, instructors who are treated fairly in terms of work division and are compensated fairly for their efforts are more likely to be successful in life. Even though Khan \& Iqbal (2020) said that, according to Maslow's hierarchy of needs, teachers may work happily only if human values are considered as valued when a task is effectively completed, treated equally when doing tasks, and given no additional stress. In order for teachers to be satisfied with their jobs, HEIs must address the needs outlined in this theory.

\section{TWO-FACTOR THEORY BY HERZBERG}

Herzberg interviewed 200 accountants and engineers for motivational research. He collected data using the critical incident technique, asking two questions: a) what brings happiness to your job when you are having a good day? And b) why do you feel so horrible about your job when you are not feeling well? Herzberg proposed that there are job-satisfiers (Motivators) linked to job content and job-dissatisfies (Hygiene Factors) linked to job context based on the feelings people have about their jobs (Falkenburg \& Schyns, 2007). Achievement, recognition, the work itself, responsibility, and growth are all powerful motivators. When it comes to hygiene, it does not motivate or fulfill, but rather, it keeps people from becoming unhappy. Factors like firm policy, management, supervision, pay, and working conditions are all part of the setting (Herzberg et al., 1959).

According to Figure 4, Motivator factors and hygiene elements are the focus of this theory, according to Mohd Norazmi et al. (2021). Herzberg (1959) asserted that high levels of motivator or stimulant variables lead to 
high levels of satisfaction. Even though hygiene variables are classified as either external or high work context, employees will not be happy if they are exposed to these conditions. This is because, according to Fauziyana et al. (2021), motivating factors such as work effectiveness, progress, and development affect a person's ability to perform well at work, while hygiene factors such as salary, working conditions, relationships with colleagues, and the role of the leader have an impact on job satisfaction. While the hygienic factor encourages workers to move around and do their jobs more efficiently to meet their goals, the motivating factor drives them to do so. According to Zaid et al. (2020), if hygiene elements are met, job satisfaction will follow, and discontent can be avoided. When the motivating element is met, it can work as a catalyst for employees to go above and beyond in their dedication to the company.

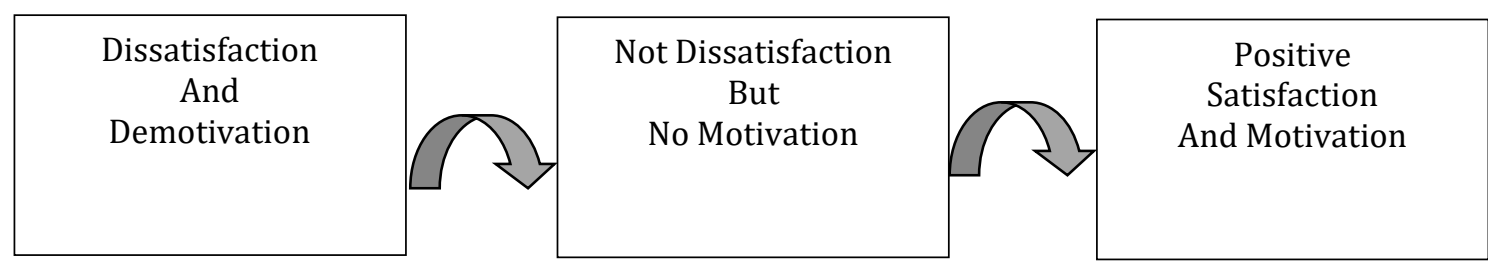

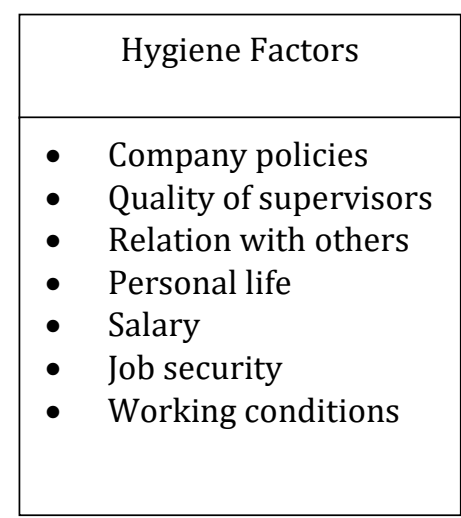

Figure 4: Herzberg's Two Factor Theory (Herzberg, 1964) Source: (Herzberg, 1964).

Teachers' job happiness and performance are determined by their motivation and the amount of influence they have. For HEIs, administrations and executives must focus on these two factors to ensure employees' job satisfaction. There are several things' leaders can do to make sure that the work in HEIs is in a positive state, such as striving to provide suitable rewards, giving teachers the space, they need to carry out their responsibilities, and treating them fairly. It is therefore possible to apply the above theory to guide universities in exercising their authority to ensure the well-being of teaching staff.

\section{EQUITY THEORY BY ADAM}

According to Adams' Equity Theory, there should be a balance between the amount of effort an employee that employee puts in and the results they receive in return. A worker's input-output ratio is compared to the ratios of other workers, and if the two are equal, equity is said to exist (Robbins \& Coulter, 2005). The distributive justice theory of equity has been intensively examined during the last few decades (Yusof \& Shamsuri, 2006). Rewards have been shown to improve employee satisfaction only when valued and seen as fair by the recipients (Durant et al., 2006).

To better understand the connection between a teacher's motivation and his or her impression of fair treatment, educators have turned to equity theory. Employees in higher education institutions, on the other hand, use equity theory to compare their own input/output ratios to those of other employee. Inputs in this context include the time, expertise, qualifications, and experience of the employee, as well as intangible human traits such as motivation and ambition, and interpersonal skills of the employees. Financial pay, perquisites (extra benefits), incentives, and work arrangements that are more flexible are some of the 
outcomes of the process. There are two ways that employees who see injustice can combat the problem: they can either adjust inputs and/or results directly (cognitive distortion) or they can leave the company altogether (Sahabuddin et al., 2021). There are significant consequences for staff morale, efficiency, productivity, and turnover in higher education institutions.

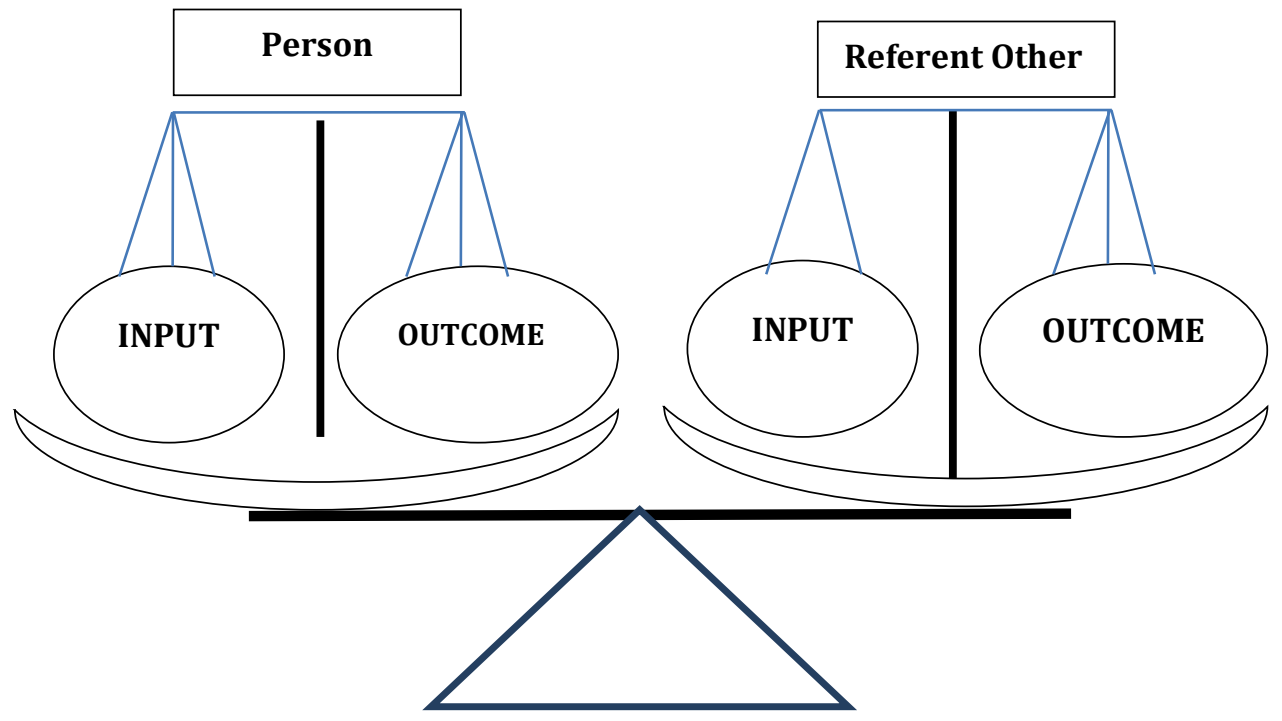

Figure 6. Adam's Equity Theory.

Source: (Adam, 1960).

The figure no. 6 shows the balance of fairness between one's own work and other colleagues' work.

\section{EXPECTANCY THEORY BY VROOM}

Individuals, according to Vroom (1964), are driven to work to get the desired results, and what they do will help them achieve their goals (Saifet al., 2012). Vroom's theory has three basic components, all of which are reliant on what he anticipates being outcomes or consequences. These are the components of Valence, Expectancy, and Instrumentality.

The strength of a person's values and personal demands for a specific outcome is referred to as their valence. The likelihood that a certain effort will result in a good performance is known as expectancy. An employee's performance is deemed instrumental if it is excellent enough to produce the intended outcome. An individual may be driven to improve their performance to obtain a promotion, for instance (Luthans, 2005). As a result of the expectation theory, different individual demands and motives are given importance (Khan, Tufail \& Ali, 2021). That means incentives used to motivate employees should have a high personal value (Durant et al., 2006). As a result, this theory is widely regarded as the most comprehensive one available (Robbins \& Coulter, 2005).

Expectancy
Perceived probability that
effort will lead to good
performance.

Figure 7. Vroom Expectancy Theory. Source: (Vroom, 1964)

\section{Satisfaction / motivation} Reason to perform

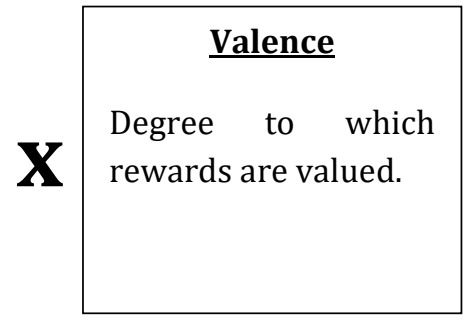


To increase the performance-outcome relationship, HEIs should implement methods that closely link incentives to performance. In addition, HEIs must ensure that the incentives provided to instructors are well-deserved and wanted by them. To enhance the effort-performance relationship, teachers should be trained to improve their talents and conviction that putting in more effort would result in better results.

\section{GOAL-SETTING THEORY BY LOCKE}

Intentions, according to Locke (1968), can be a

significant source of drive and happiness (Saifet al., 2012). High-performance results from setting difficult goals rather than easy ones and receiving feedback results in higher performance than not receiving any input. Similarly, setting hard, precise goals yields better results than setting general goals like "do your best" (Saifet al., 2012). Furthermore, people perform better when they are driven by clear objectives and receive frequent feedback that highlights the differences between their actual performance and their desired performance. All the research that investigated the goalsetting hypothesis found that giving people feedback on their progress toward their goals was a powerful motivator (Robbins \& Coulter, 2005). A little workplace challenge doesn't hurt either. Employees are driven by well-defined goals and feedback.

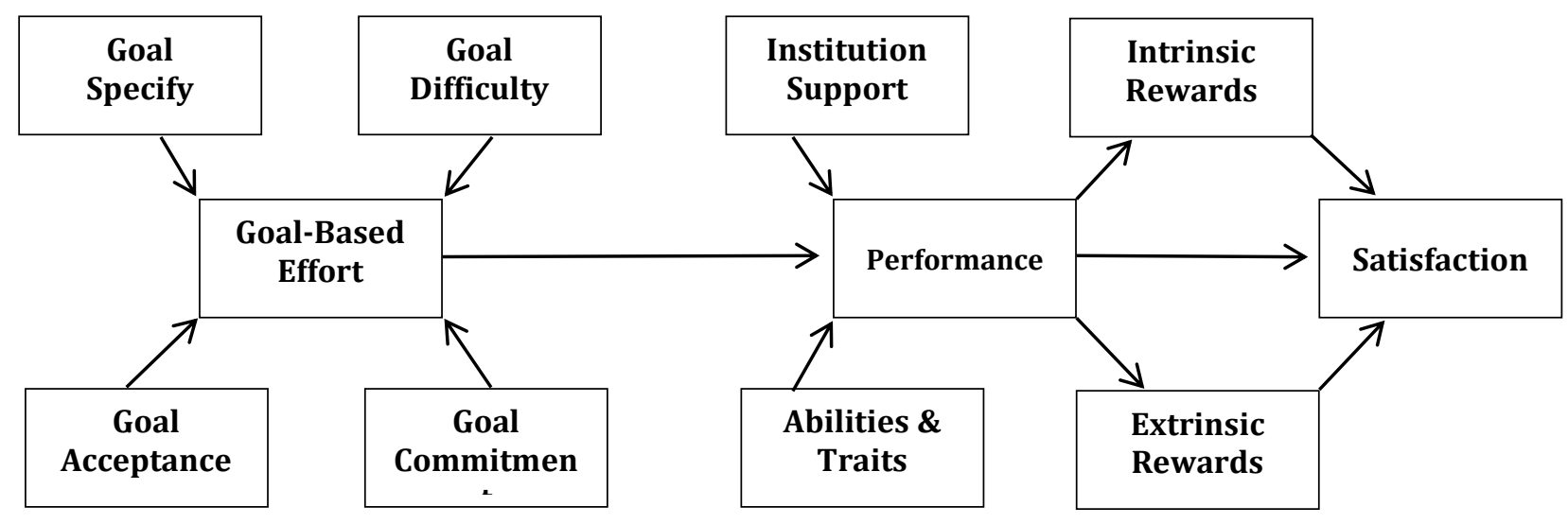

Figure 7. Locke's Goal Setting Theory.

Source: (Locke, 1968).

The goal-setting model of employee motivation has been extensively studied and is fundamentally connected to great performance. By setting good goals at the beginning of the year and tracking progress toward those goals, teachers can focus on improving a few specific, high-impact skills rather than trying to improve everything at once. According to goal-setting theory, achieving challenging goals necessitates focusing on issues, increasing the relevance of the goals, and fostering persistence. To better understand phenomena such as the mentality and perception of employees that they successfully contribute to HEIs' performance, goalsetting theory can be coupled with cognitive theories (Moynihan \& Pandey, 2007).

\section{CONCLUSION AND IMPLICATIONS}

Eventually, the study's major goal was to combine ideas on job satisfaction in Pakistani higher education. To gather literature on job satisfaction of employees, the study used famous theories of motivation/satisfaction to relating this to the academic staff of HEIs to draw the conclusion. These theories have been thoroughly examined based on the various points of view and components that go into determining the job satisfaction of academic staff. A sense of fulfillment in one's work is essential for teachers since they act as intermediaries in information transfer. As a result, teachers will cultivate a positive self-image and be inspired to do an even better job in the future.

Although theories have no inherent good or bad, their applicability varies depending on the situation. Most job satisfaction models have been developed by authors in the developed world, with the assumption that these models can be applied globally. For instance, most models emphasize individualism and achievement, while Pakistan is considered a collectivist culture. In a collectivist culture, the demands of a group or community take precedence over those of an individual. 
The importance of kinship, family, and community cannot be overstated. When people want to build harmony, they tend to work together, and group cohesion is highly regarded.

The new fields of human psychology research, such as the positive psychology movement, require these theories to be reconstructed in accordance with the new areas of research. According to this line of thinking, psychology has only focused on managing negative, abnormal aspects of human behavior. A scientific technique for identifying and promoting the elements that enable individuals, groups, organizations, and communities to survive and prosper has emerged because of positive psychology. Optimism, hope, happiness, resilience, confidence, and self-efficacy are some examples of these traits. Theories of job satisfaction must thus be put to the test at Pakistani HEIs against these new positive psychology aspects and their impact on human behavior at the individual, group, and organizational levels.

\section{CULTURAL LIMITATIONS}

Most motivation/satisfaction theories were established by natives for natives in the United States. As a result, we must exercise caution when believing that these theoretical models would perform equally well across cultures. For example, almost all of the theories place a premium on individuality and success, both of which are pro-American traits (Robbins, 2005). As a result of these variables, the tale of these theories varies from culture to culture. Religion, for example, associates differing values with distinct needs and motivations, altering the relevance of different requirements in different religious beliefs (Luthans, 2005), modifying the hypotheses of the original theories and their execution.

\section{FUTURE RESEARCH}

This study uses a theory-based approach to drawing conclusions rather than an empirical approach, and only 5 theories were chosen. Future studies can consider other theories of satisfaction and motivation. Secondly, these theories are defined in the context of higher educational institutes. It would be interesting to relate these theories to any other to generalize the results. A comparative study can also be conducted of old and new theories of satisfaction and motivation to set new directions.

\section{REFERENCES}

Clark, A., Oswald, A.J., \&Warr, P. (1996). Is job satisfaction U-shaped in age? Journal of Occupational and Organisational Psychology, 69(1), 57-81.

Durant, R.F., Kramer, R., Perry, J.L., Mesch, D., \&Paarlberg, L. (2006). Motivating employees in a new governance era: The performance paradigm revisited. Public Administration Review, 66(4), 505-514.

Een Nurhasanah, Uah Maspuroh, Rina Marlina S. Psi, M. Pd, Mohd Norazmi bin Nordin. (2021). Arifin C. Noor's Drama "Matahari Di Sebuah Jalan Kecil" As A Media for Literature Learning in Senior High School: A Study of The Structure and Psychological Value. Psychology and Education 58(2): 1131511328.

Falkenburg, K., \& Schyns, B. (2007). Work satisfaction, organizational commitment and withdrawal behaviour. Management Research News, 30(10), 708-723.

Firkhan Ali Bin Hamid Ali, Mohd ZalishamJali, Mohd Norazmi bin Nordin. (2021). Preliminary Study on It Security Maintenance Management in Malaysia Organizations. PalArch's Journal of Archaeology of Egypt / Egyptology, 18(1), 4061-4073.

Gunlu, E., Aksarayli, M., \&Perçin, N.Ş. (2010). Job satisfaction and organizational commitment of hotel managers in Turkey. International Journal of Contemporary Hospitality Management.

Herzberg, F., Mausner, B., \& Snyderman, B. (1959). The motivation to work. New York: Wiley.

Javeria, A., Rizwan, M., Khan, A., Hameed, A., Neem, Q., \& Subctageen, M. (2013). Examining the

Antecedents of Job Satisfaction and further its impact on Organizational Commitment. Journal of Public Administration and Governance, 3(3), 317334.

Junaid, A., Bashir, F., Nasim, I., \& Ahmad, R. (2021). Understanding Affective, Normative \& Continuance Commitment through the Lens of Training \& Development. iRASD Journal of Management, 3(2), 105-113.

Kaur, A. (2013). Maslow's Need Hierarchy Theory: Applications and criticisms. Global Journal of Management and Business Studies, 3(10), 10611064.

Khan, A. J., \& Iqbal, J. (2020a). Training and Employee 
Commitment: The Social Exchange Perspective. Journal of Management Sciences, 7(1), 88-100.

Khan, A. J., \& Iqbal, J. (2020b). Do High Performance Work Practices Increase the Organizational Performance of Public Sector Companies? An Investigation of Mediation Mechanism. Pakistan Journal of Social Sciences (PJSS), 40(2), 1007-1021.

Khan, A. J., Tufail, S., \& Ali, A. (2021). Factors Affecting Performance of Small \& Medium Enterprises: The Mediating Role of Knowledge Management. Pakistan Journal of Humanities \& Social Sciences, 9(2), 197-209. doi:https://doi.org/10.52131/pjhss.2021.0902.01 29

Khan, A. J., Shah, S. Z. A., Bashir, F., \& Iqbal, J. (2021). Antecedents and Consequences of Green Human Resource Management in Oil and Gas Companies of Pakistan. Sustainable Business and Society in Emerging Economies, 3(3), 339-351. https://doi.org/10.26710/sbsee.v3i3.1985

Kebede, A.M., \& Demeke, G.W. (2017). The influence of leadership styles on employees' job satisfaction in Ethiopian public universities. Contemporary Management Research, 13(3), 165-176.

Locke, E.A. (1968). Toward a theory of task motivation and incentives. Organizational Behavior \& Human Performance, 3(2), 157-189.

Luthans, F. (2005). Organizational behavior. 10th ed. Boston, MA: McGraw Hill.

Mohammad, J., Habib, F.Q. \&Mohmad, A.A. (2011). Job satisfaction and organisational citizenship behaviour: An empirical study at higher learning institutions. Asian Academy of Management Journal, 16(2), 149-165.

Moynihan, D.P., \& Pandey, S.K. (2007). Finding workable levers over work motivation comparing job satisfaction, job involvement, and organisational commitment. [Online]. Available from: http://ssrn.com/abstract=975290 Accessed: 13 March 2019.

Norazmi, N. (2020). Effect Size for Model of the Influence of Headmasters Leadership on Teacher Task Load and Teacher Job Satisfaction of Special Education Integration Program. International Journal of Phycpsocial Rehabilitation, 24(10), 2020: 21022112.

O'Leary, P., Wharton, N., \& Quinlan, T. (2009). Job satisfaction of physicians in Russia. International
Journal of Health Care Quality Assurance, 22(3), 221-231.

Okoli, I.E. (2018). Organizational climate and job satisfaction among academic staff: Experience from selected private universities in Southeast Nigeria. International Journal of Research in Business Studies and Management, 5(12), 36-48.

Robbins, S.P., \& Coulter, M. (2005). Management. New Delhi: Pearson Education.

Rosnee Ahad, Mohamad Zaid Mustafa, Suhaimi Mohamad, NurHanimSaadah Abdullah, Mohd Norazmi Nordin (2021). Work Attitude, Organizational Commitment and Emotional Intelligence of Malaysian Vocational College Teachers. Journal of Technical Education and Training, 13(1), 15-21.

Saif, S.K., Nawaz, A., Jan, F.A., \& Khan, M.I. (2012). Synthesizing the theories of job satisfaction across the cultural/attitudinal dimensions. Interdisciplinary Journal of Contemporary Research in Business, 3(9), 1382-1396

Stankovska, Angelkoska, Osmani, Grncarovska: Job Motivation and Job Satisfaction among Academic Staff in Higher Education, Current Business and Economics Driven Discourse and Education: Perspectives from Around the World BCES Conference Books, Volume 15. Sofia, Bulgaria, 2017.

Toker, B. (2011). Job satisfaction of academic staff: An empirical study on Turkey. Quality Assurance in Education, 19(2), 156-169.

Van den Brink, M., Fruytier, B., \& Thunnissen, M.: Talent management in academia: performance systems and HRM policies. Human Resource Management Journal, 23(2), 2013.

Vroom, V. H. (1964). Work and motivation. New York: Wiley.

Weihrich, H., \& Koontz, H. (1999). Management: A global perspective. 10th ed. New York: McGraw-Hill Inc.

Wisniewska, Grudowski: High-quality academic teachers in business school. The case of The University of Gdansk, Poland, Total Quality Management, 27(10), 1158-1170, 2016.

Yusof, A.A. \&Shamsuri, N.A. 2006. Organizational justice as a determinant of job satisfaction and organizational commitment. Malaysian Management Review, 41(1), 47-62.

Zaid, M., Norazmi, N. \& Abdul Rasid, A. R. (2020). 
Regression between Headmaster Leadership, Task Load and Job Satisfaction of Special Education Integration Program Teacher. Universal Journal of
Educational Research 8(4), 1356-1362. Doi: 10.13189/ujer.2020. 080428B20B16:B24: B31

Publisher's note: EScience Press remains neutral with regard to jurisdictional claims in published maps and institutional affiliations. (c) (i) use, sharing, adaptation, distribution and reproduction in any medium or format, as long as you give appropriate credit to the original author(s) and the source, provide a link to the Creative Commons license and indicate if changes were made. The images or other third-party material in this article are included in the article's Creative Commons license, unless indicated otherwise in a credit line to the material. If material is not included in the article's Creative Commons license and your intended use is not permitted by statutory regulation or exceeds the permitted use, you will need to obtain permission directly from the copyright holder. To view a copy of this license, visit http://creativecommons.org/licenses/by/4.0/.

(C) The Author(s) 2021. 